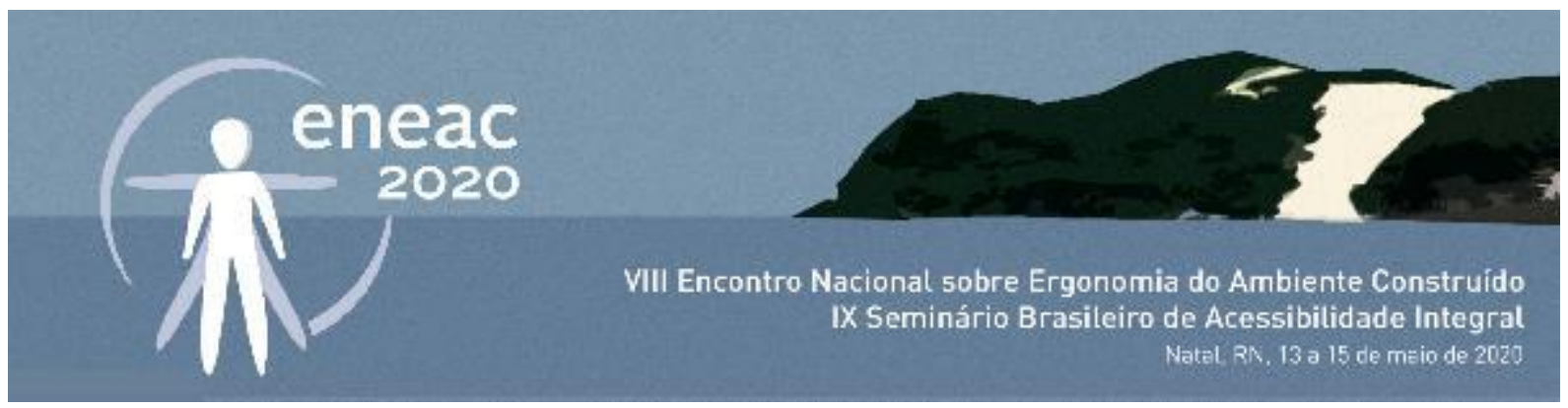

\title{
Análise sintática de dormitórios acessíveis em hotéis da cidade de Natal/RN
}

\author{
Syntactic analysis of accessible hotel rooms in the city of Natal-RN
}

\author{
THATYANE MACEDO ALVES DE MORAIS \\ Arquiteta e Urbanista, Universidade Federal do Rio Grande do Norte, \\ thatyanemorais@live.com
}

BRENO CÂMARA CAVALCANTI

Engenheiro Mecânico, Universidade Federal do Rio Grande do Norte, brenocc@hotmail.com

\section{RESUMO}

O estudo da sintaxe espacial tem sido utilizado desde o início dos anos 1980 como importante ferramenta capaz de medir o nível de integração entre ambientes construídos. Este artigo apresenta os resultados de análises sintáticas realizadas em relação a dormitórios acessíveis de hotéis na cidade de Natal, Rio Grande do Norte. O objetivo desta pesquisa consiste em comparar as características dos ambientes construídos de hotéis em Natal-RN com alguns exemplos analisados em projetos de hotéis de outros estados disponíveis em páginas eletrônicas, de modo a identificar possíveis segregações entre os dormitórios acessíveis e as áreas comuns que possam ocasionar a presença de longos e exaustivos percursos para hóspedes autônomos com deficiência. Para a obtenção dos resultados desta análise foi utilizado o software Dephtmap ${ }^{\circledR}$ que calculou as distâncias métricas a partir do ponto de acesso do hall das suítes até as acessíveis com base na planta baixa de cada edifício. Foi levado em consideração que o percurso de acesso do hall de entrada do edifício até o hall de acesso aos dormitórios seria irrelevante, conforme as características comumente encontradas. Conclui-se que para todos os hotéis estudados situados em Natal-RN a disposição dos dormitórios acessíveis satisfaz o critério de integração enquanto os hotéis da região sudeste apresentaram resultados desfavoráveis uma vez que estes ambientes se mostraram segregados em relação aos demais.

PALAVRAS-CHAVE: sintaxe espacial, hotéis, acessibilidade.

\section{ABSTRACT}

The study of spatial syntax has been used since the early 1980 s as an important tool capable of measuring the level of integration between built environments. This paper presents the results of syntactic analyzes carried out in relation to accessible hotel rooms in the city of Natal, Rio Grande do Norte. The objective of this research is to compare the characteristics of the built environments of hotels in Natal-RN with some examples analyzed in hotel projects from other states available on web pages, in order to identify possible segregations between accessible dorms and common areas that may cause 


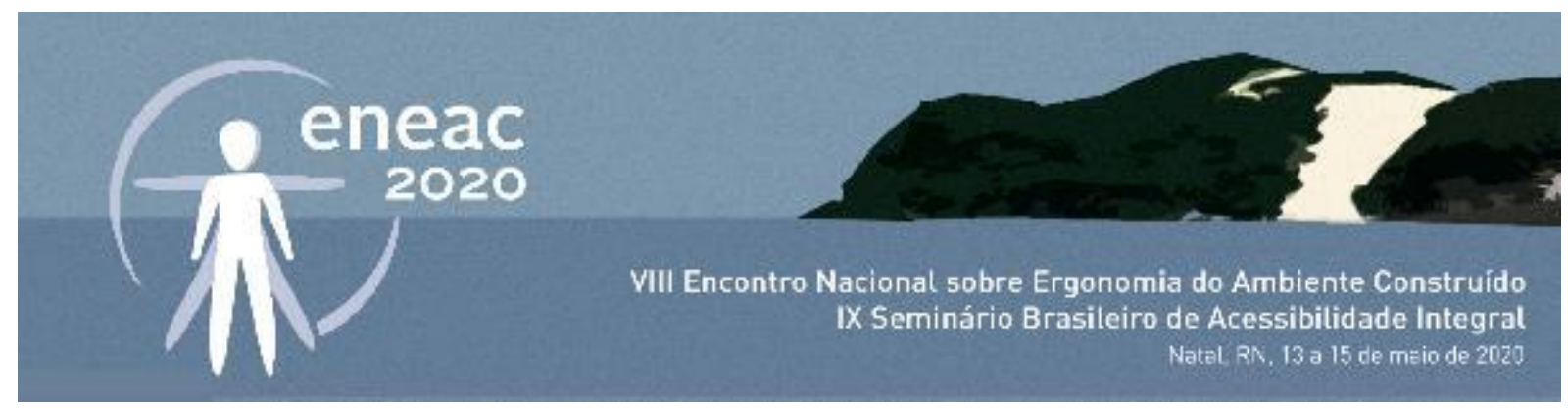

the presence of long and exhausting routes for autonomous guests with disabilities. To obtain the results of this analysis, the software Dephtmap ${ }^{\circledR}$ was used, which calculated the metric distances from the access point of the suites' hall to those accessible based on the floor plan of each building. It was taken into account that the access route from the building's entrance hall to the dormitory access hall would be irrelevant, according to the characteristics commonly found. It is concluded that for all the studied hotels located in Natal-RN, the availability of accessible dormitories satisfies the integration criterion while the hotels in the southeast region presented unfavorable results since these environments were segregated in relation to the others.

KEYWORDS: spatial syntax, hotels, accessibility.

\section{INTRODUÇÃO}

Acredita-se que as questões relativas à acessibilidade são atemporais e devem abranger todo e qualquer tipo de edificação, por uma questão eminentemente de garantir inclusão social a todos, de acordo com os princípios do Desenho Universal. Este tem como premissa a concepção de produtos, ambientes, programas e serviços a serem usados por todas as pessoas, sem necessidade de adaptação ou de projeto específico, incluindo os recursos de tecnologia assistiva e é obrigatório para concepção de ambientes desde 2004, conforme o Decreto Federal 5.296.

Em janeiro de 2016 entrou em vigor a Lei Federal 13.146, denominada Lei Brasileira de Inclusão da Pessoa com Deficiência que em seu artigo 45 determina que os hotéis, pousadas e similares devem ser construídos observando-se os princípios do desenho universal, além de adotar todos os meios de acessibilidade. Além disso em seu parágrafo primeiro estipula que os estabelecimentos já existentes deverão disponibilizar pelo menos $10 \%$ (dez por cento) de seus dormitórios acessíveis, garantida, no mínimo, 1 (uma) unidade acessível. Entretanto, este artigo apesar de ter entrado em vigor no ano de 2016 com prazo a seguir o cumprimento de 24 meses, foi apenas em março de 2018 que foi publicado o Decreto 9.296 que regulamenta este artigo sobre hotéis da Lei de Inclusão. Desta forma, considerando o potencial turístico da cidade de Natal, tornou-se de relevante importância a realização deste estudo.

Natal figura-se entre os 15 destinos mais visitados do Brasil, por motivo de viagem a lazer, de acordo com o estudo da demanda turística do Anuário Estatístico de Turismo de 2017 do Ministério de Turismo. Tendo em vista esses dados referentes a notável procura da cidade e atendendo as legislações vigentes, o presente estudo aplicará a sintaxe espacial (SE) como principal ferramenta de projeto para a identificação e diagnóstico das distâncias métricas dos quartos acessíveis dos hotéis em análise. Os projetos foram disponibilizados pela Secretaria Municipal de Meio Ambiente e Urbanismo - SEMURB, da cidade de Natal/RN.

Criada por Bill Hillier e seus colaboradores da Universidade de Londres, no começo da década de 1980, a Teoria da Sintaxe Espacial busca descrever a configuração do traçado e as relações entre espaço público e privado através de medidas quantitativas, as quais permitem entender aspectos importantes do sistema urbano e suas relações de interdependência entre os diversos elementos constituintes do sistema, como ruas, quadras, ambientes de uma edificação, entre outros elementos tais como a acessibilidade e a distribuição de usos do solo. A sintaxe espacial "visa compreender as 


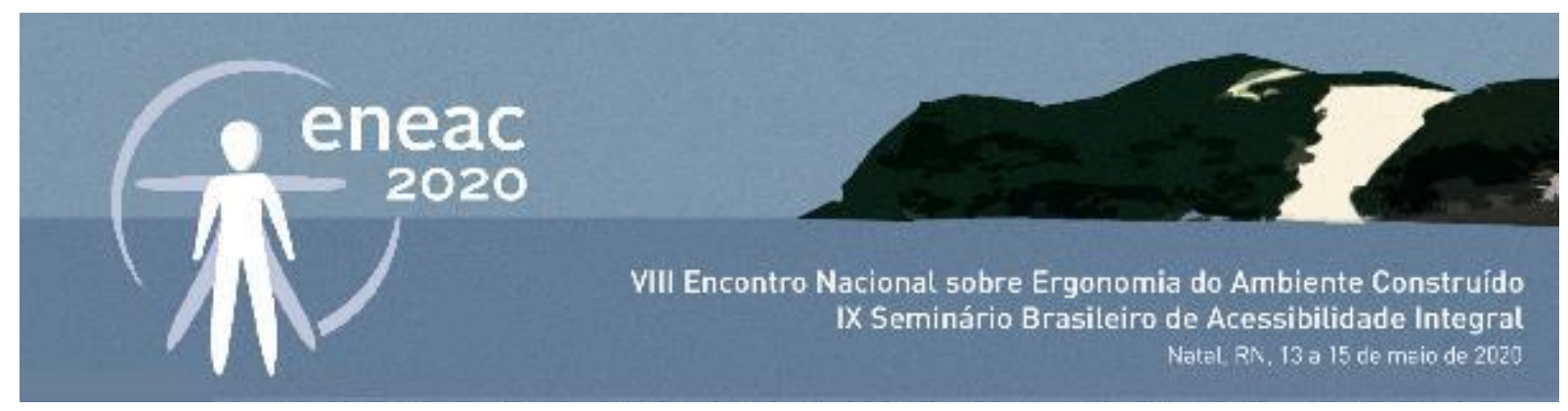

relações entre a configuração de cidades e edifícios e o modo como as pessoas permanecem ou se movem nos espaços, além das implicações sociais disto." (HOLANDA, 2011, p:13).

\begin{abstract}
A sintaxe espacial tem seu apelo ao pesquisador, professor ou profissional da arquitetura por fornecer subsídios de ordem teórica e analítica que advém da observação do próprio ambiente construído objeto da disciplina arquitetônica -, e por expressar-se por meio gráfico - forma de comunicação de ideias familiar ao arquiteto e urbanista (RAMOS, 2018, p: 37).
\end{abstract}

Durante o processo de análise serão consideradas algumas variáveis e conceitos próprios da SE, tais como: acessibilidade ${ }^{\mathrm{i}}$, conectividade ${ }^{\mathrm{ii}}$, passo topológico ${ }^{\mathrm{iii}}$ e integraçãoiv.

Tendo em vista o atual cenário legal com relação ao ramo da hotelaria, o objetivo deste estudo é de identificar possíveis segregações e a consequente presença de longos e exaustivos percursos para hóspedes autônomos com deficiência comparados com os percursos dos dormitórios comuns em relação ao hall de entrada da área das suítes em hotéis de outros estados cujas plantas baixas encontravam-se disponíveis eletronicamente em páginas de livre acesso.

\title{
2 METODOLOGIA
}

Este estudo tem base nos princípios da Sintaxe Espacial cuja teoria parte de pressupostos que pessoas tendem a se mover em linha reta, em busca das menores distâncias possíveis entre dois pontos, medidas em passos topológicos; interagem em espaço convexos, de onde todos os pontos podem ver todos os demais; e que se movem no ambiente construído ao mesmo tempo que veem campos visuais que mudam constantemente de formato (HILLIER e VAUGHAN, 2007; BENEDIKT, 1979).

O objeto desta pesquisa surgiu após a verificação, nos projetos dos três hotéis inicialmente analisados, de que em todos havia aparentes segregações dos dormitórios acessíveis em relação aos demais fundada na organização da localização desses de acordo com a planta baixa do local, levantando a hipótese de que esta segregação poderia estar comumente presente em quaisquer hotéis, havendo a necessidade de investigação. Para tal decidiu-se então avaliar hotéis em Natal-RN com base também nas plantas baixas disponibilizadas pela SEMURB, valendo-se da publicidade dos processos.

O conceito de integração/segregação para a Sintaxe Espacial está ligado à distância topológica de um espaço em relação aos demais. O espaço mais integrado é aquele que tem a menor distância topológica para todos os outros espaços (HILLIER, 2007). Quanto mais acessível um espaço é em relação à média do sistema a qual faz parte, mais integrado ele é. Quanto menos, mais segregado. Acessibilidade espacial determina a maior ou menor facilidade com que locais são acessados pela população.

Análise Sintática do Espaço (ASE) utiliza relações matemáticas aplicadas por programas computacionais à configuração da malha dos ambientes, representada por espaços convexos e suas conexões para mensurar propriedades espaciais - tais como a de conectividade e integração - e quantificá-las em valores em uma escala cromática, expressivos de distintos graus de acessibilidade ou segregação, permeabilidade ou existência de barreiras, potencial de movimento ou permanência de pessoas nos espaços edificados da cidade. 


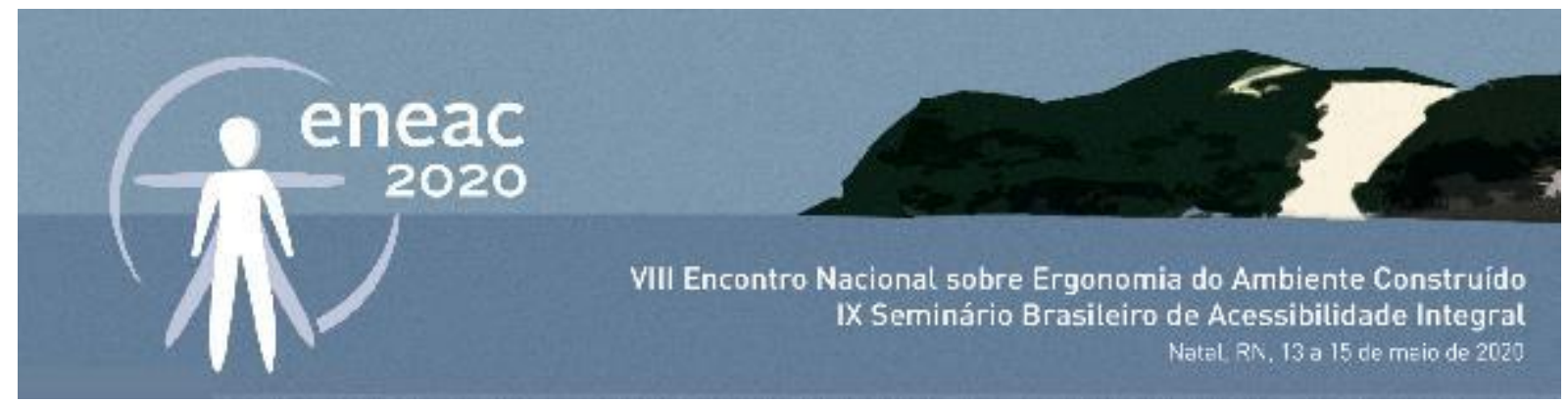

O primeiro hotel pesquisado foi o Hotel Linx International Airport Galeão. Projetado pelo escritório de arquitetura OSPA Arquitetura e Urbanismo e executado em 2013, está localizado à Avenida Vinte de Janeiro, $s / n^{\circ}$ - Galeão, Ilha do Governador, Rio de Janeiro, próximo ao Aeroporto Internacional Antônio Carlos Jobim cujas fachada e planta baixa estão representadas nas Figuras 1 e 2, respectivamente.

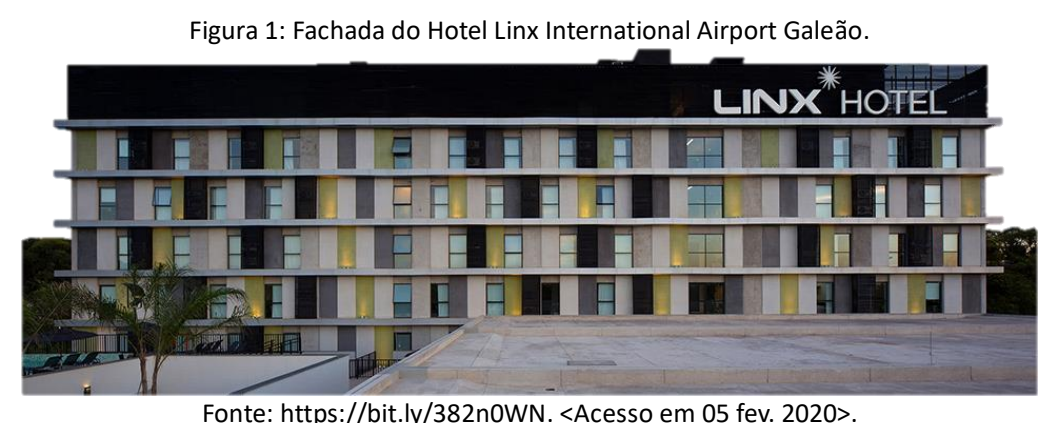

Figura 2: Planta baixa do Hotel Linx International Airport Galeão com quartos acessíveis localizados nos números 11 do lado esquerdo.

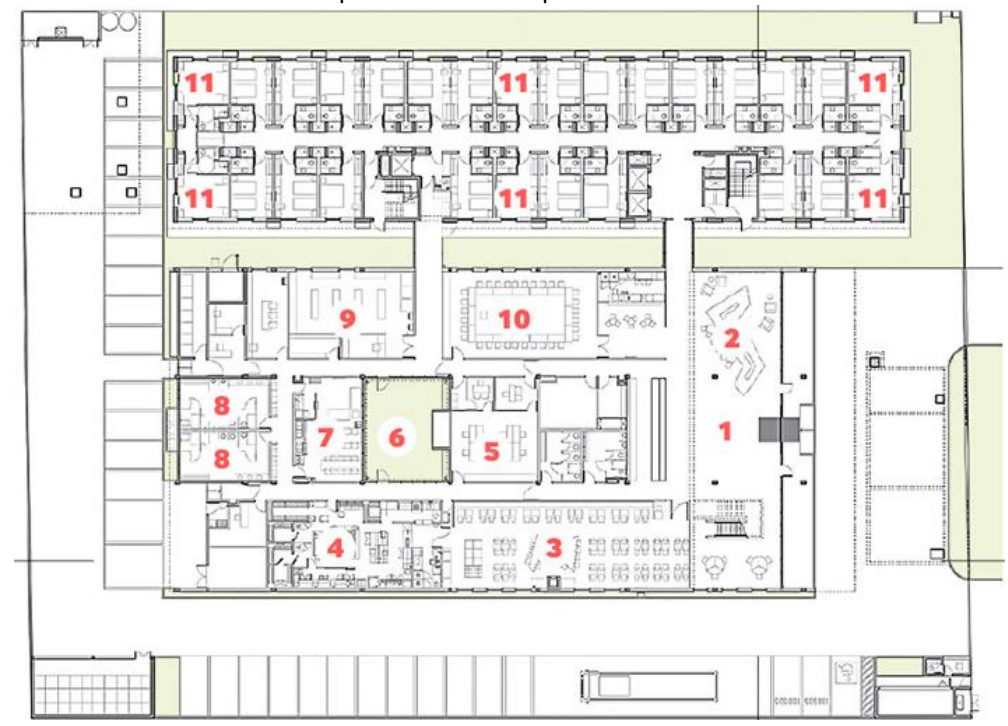

Fonte: https://bit.ly/382nOWN. <Acesso em 05 fev. 2020>.

Visualmente, sem prévia análise, pode-se perceber que os dormitórios acessíveis são ambientes terminais e de menores valores de integração, pois são menos conectados que os demais de seu sistema, portanto, segregados. A conectividade mede o número de espaços imediatamente conectados a um espaço de origem. Esta previsão foi confirmada através da representação das configurações do espaço através de grafo justificado mostrado nas Figuras 3 e 4 . Ou seja, uma configuração espacial em que as unidades espaciais correspondem a nós, e as relações de permeabilidade ou visibilidade entre as mesmas representam conexões. Os grafos são estruturados em níveis sobrepostos, correspondentes a passos sintáticos que estabelecem a profundidade do 


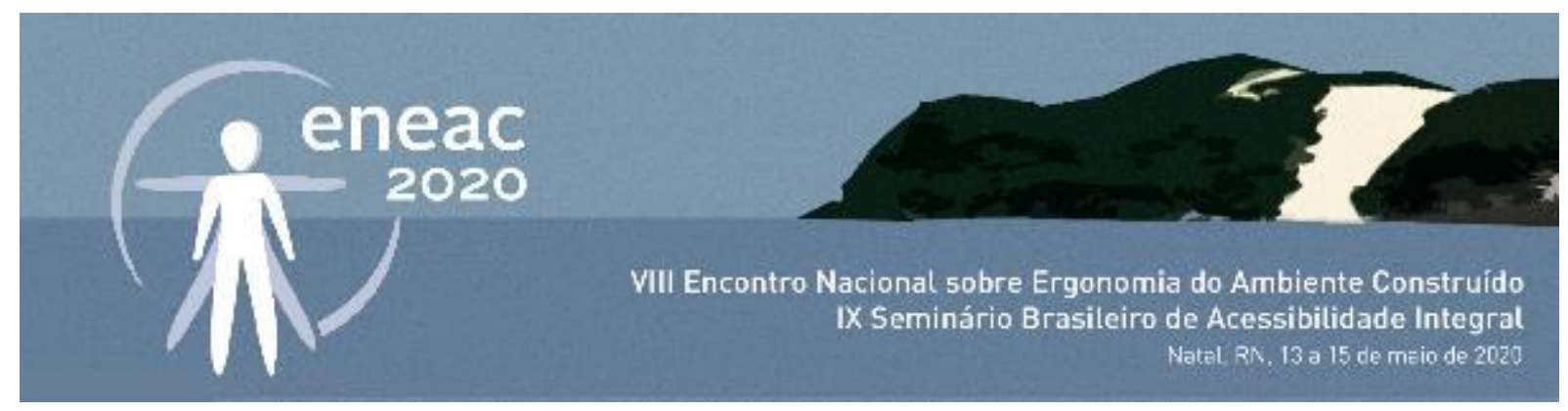

sistema. Alinhando um grafo a partir de um nó, tem-se a distância topológica, que é a menor distância entre dois nós de um grafo em número de passos, a partir do nó-raiz.

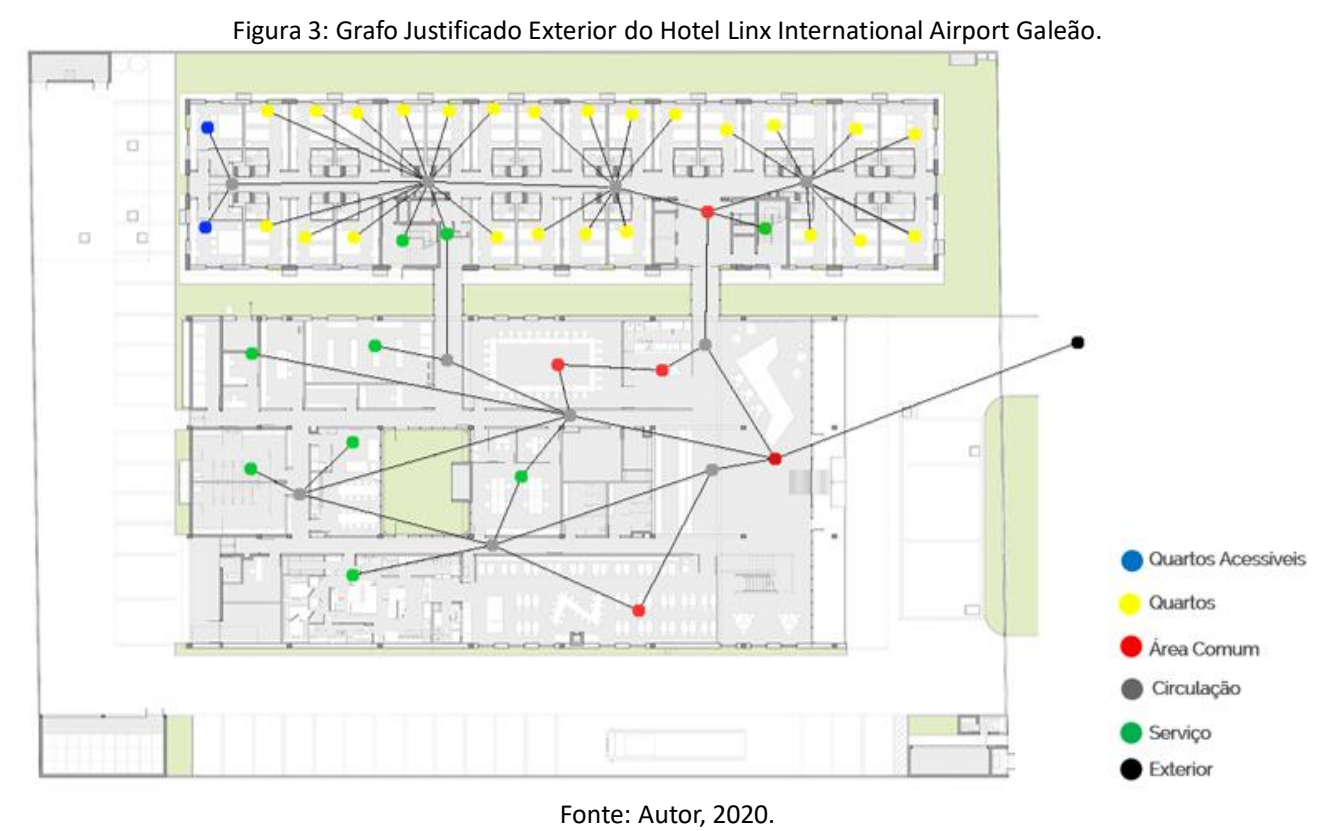

Justificando este grafo no seu exterior, simulamos esquematicamente ambientes internos e as diferenças de configuração ao modificar como estes se relacionam entre si e o exterior, resultando em distintos níveis de profundidade para acessar os espaços. $O$ exterior é o primeiro ponto de acesso da rota da edificação. Para a elaboração deste grafo, foi utilizado o software Jass ${ }^{\circledR}$.

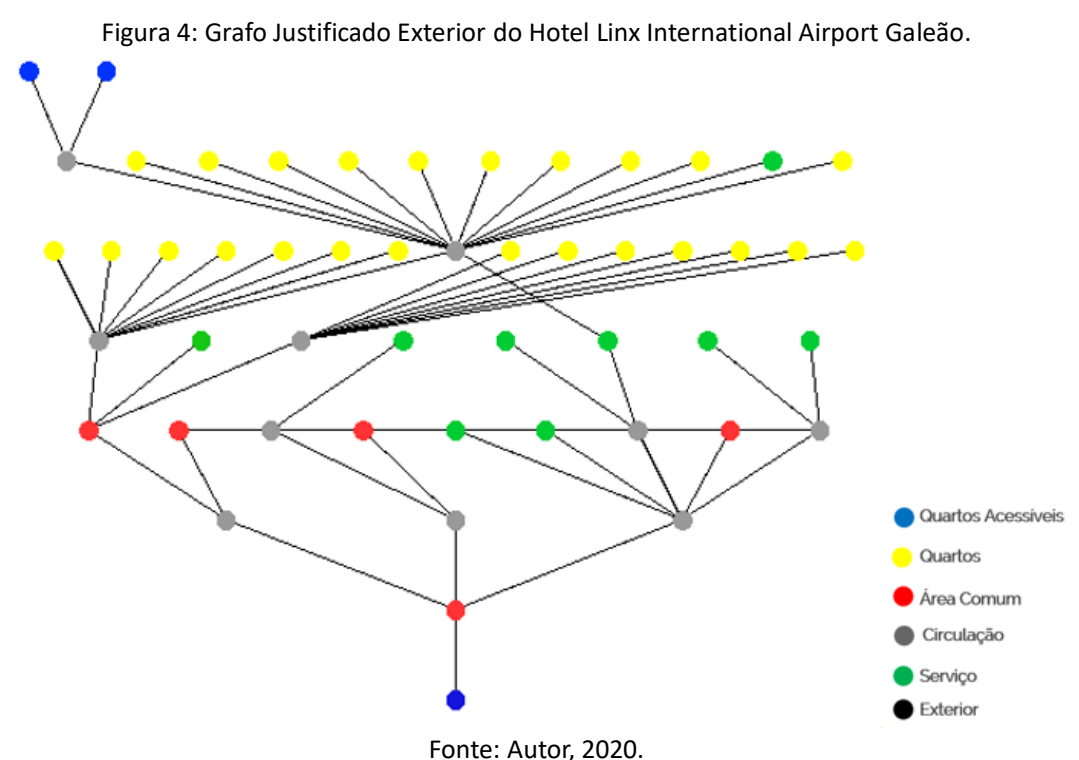




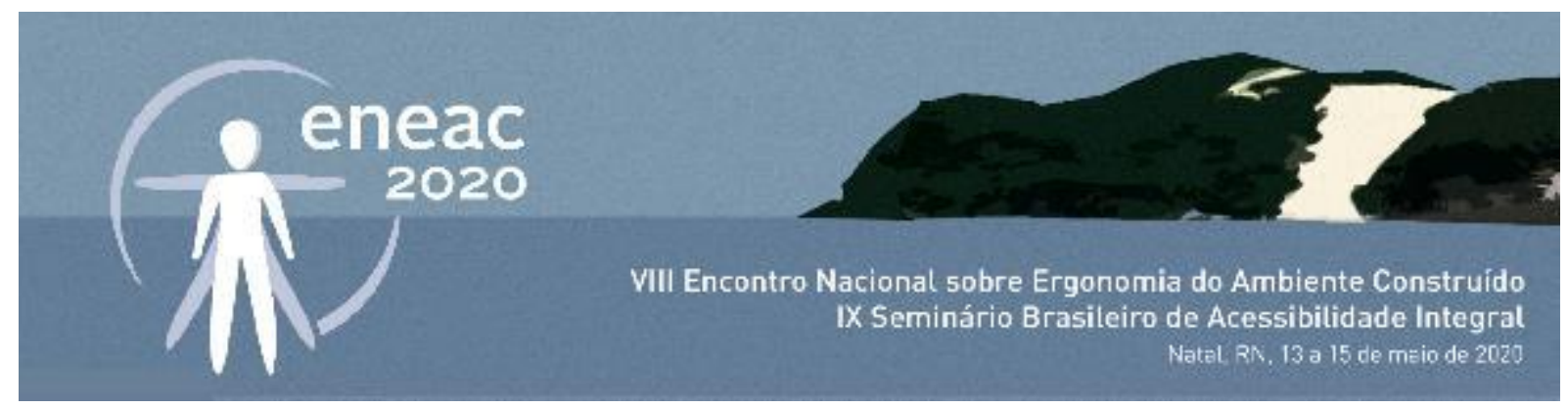

Segundo Hillier et al. (1993), a integração mede a profundidade média de uma linha em relação a todas as outras linhas do sistema, sendo que as linhas mais integradas - ou acessíveis - são aquelas que estão mais rasas, e as mais segregadas, as que se encontram mais profundas quanto às demais. A medida de integração é a mais utilizada pela ASE, e permite que sejam verificados níveis de acessibilidade. Este também é capaz de calcular os valores de integração o RRA (Real Relative Asymmetry). Os valores de RRA, que permite uma correta comparação entre sistemas de diferentes tamanhos e variam para menos ou mais de 1 , entre 0,4 a 0,6 representam sistemas muito integrados, enquanto aqueles que tendem ou são superiores a 1 refletem malhas com áreas segregadas. A Figura 5 apresenta os valores de RRA para o Hotel Linx.

Figura 5: Valores de RRA para Hotel Linx International Airport Galeão.

\section{Comparação integração (RRA)}

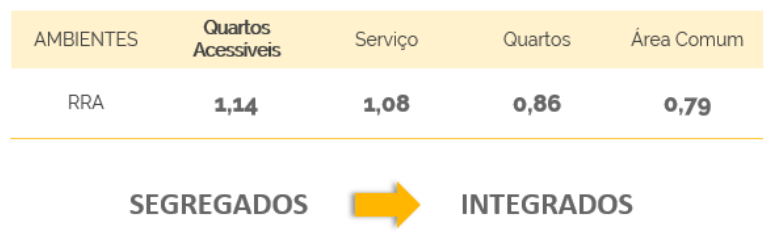

Fonte: Autor, 2020.

Foi realizada análise da caracterização topológica e métrica de um ponto para todos os outros por meio do Step Depth, técnica utilizada para estudar a profundidade de passos de um ponto específico do sistema em relação ao todo. O Step Depth mostra a quantos passos topológicos todos os ambientes estão do ponto escolhido. O resultado final desta técnica é um Grafo Visual, ou VGA Visual Graph Analisys que pode ser empregado tanto com relação a distância métrica, como também angular e topológica conforme apresentado na Figura 6. O VGA é um grafo não direcional conectado todos os pontos intervisíveis em um grid baseado na escala humana.

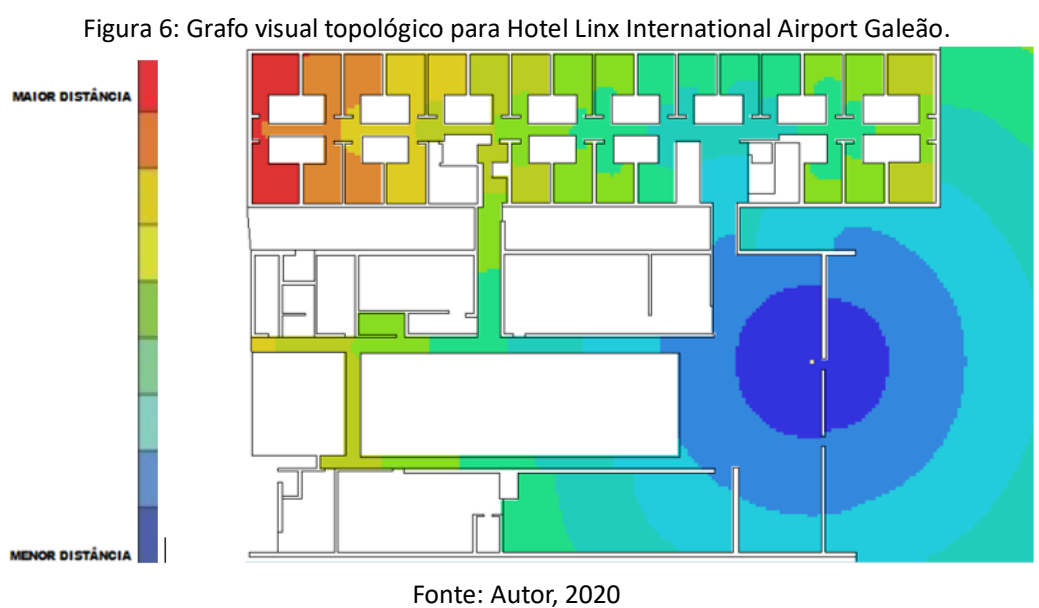




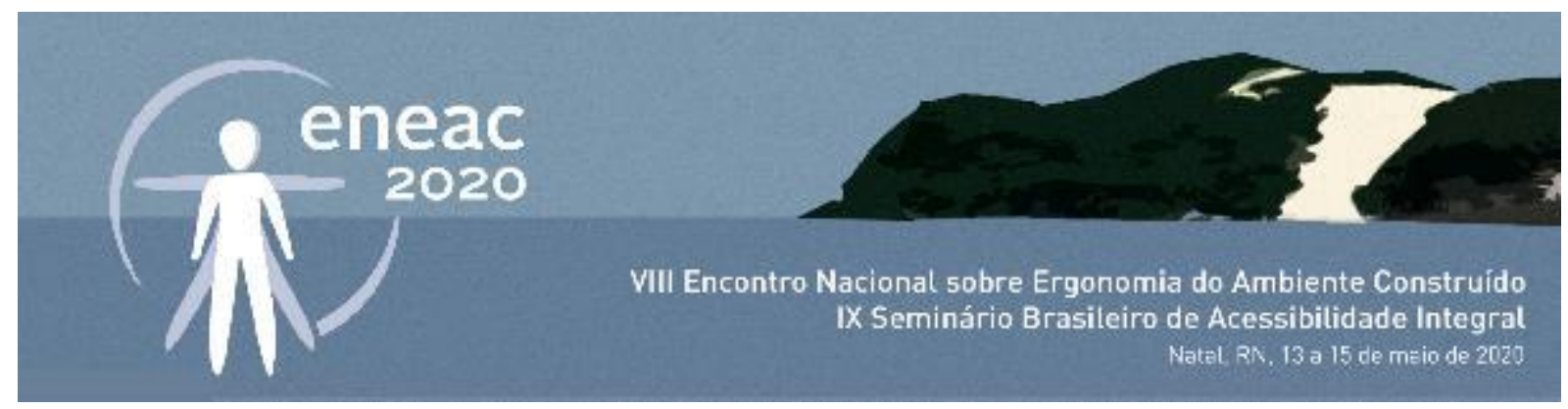

Esta teoria incialmente não leva em conta condicionantes não espaciais como critério de análise, portanto as considerações são feitas através da leitura que o software fornece da configuração espacial da edificação. Diante disto, os ambientes de pouca ou nenhuma permanência dos hóspedes não foram considerados, pois não é o principal propósito da edificação, bem como as rotas a estes ambientes, o que se espera ter contribuído para que o resultado se aproximasse do objetivo proposto, uma vez que nestes espaços as pessoas não tenderão a circular, então os mesmos não influenciariam na leitura do espaço.

Foi possível também identificar ainda áreas afetadas em relação à segregação e a profundidade topológica, o que correlacionadas com o tipo de usuário e a função do ambiente, poderiam ser avaliadas como áreas críticas ou não. Esta avaliação é muito importante quando se observa a necessidade de transparecer boa primeira impressão e posteriormente atender às expectativas dos hóspedes e satisfação dos mesmos, portanto, a eficiência desta ação é questão fundamental.

\section{RESULTADOS E DISCUSSÕES}

Objetivando aumentar a quantidade de análises comparativas, recorreu-se ao estudo de hotéis de outros estados disponíveis em páginas eletrônicas (Hotel Aliah e Valongo Brasil, ambos no estado de São Paulo), visto a complexidade de obtenção de projetos da cidade em estudo, Natal.

\section{Hotel Aliah - Campinas, SP}

Este projeto ideado pelo escritório de arquitetura Arkiz + Hiperstudio, em 2012, foi vencedor de um concurso organizado pela empresa Aliah, que promove o desenvolvimento sustentável por meio de práticas e negócios que sejam rentáveis e de impacto socioambiental positivo. O objetivo do concurso era desenvolver o projeto de um complexo hoteleiro ecossustentável de alto padrão para atender a Copa de 2014, a ser implantado na região de Campinas - SP. A Figura 7 ilustra o Grafo visual topológico para este hotel.

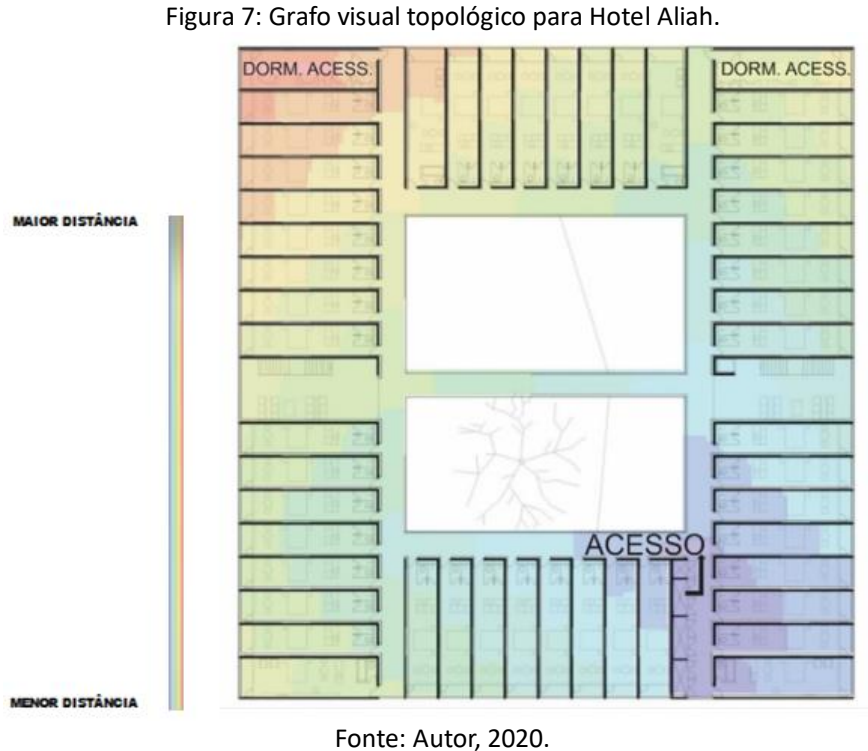




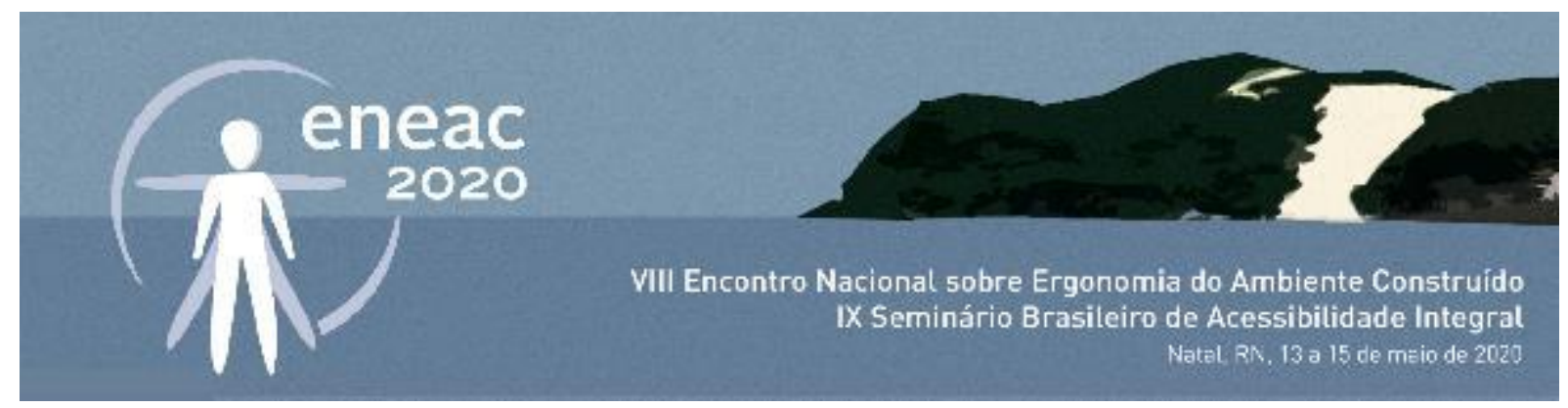

É possível verificar que os dormitórios acessíveis encontram-se nas regiões vermelhas e alaranjadas do grafo visual indicando que estão segregados em relação aos demais.

\section{Valongo Brasil - Santos, SP}

Edifício projetado pelo escritório de arquitetura Aflalo/Gasperini arquitetos, para que inicialmente fosse um prédio exclusivamente comercial, acabou por acolher um hotel. Com isso, o partido arquitetônico recebeu adequações que tornaram o desenho menos simétrico. As salas comerciais, antes concebidas como módulos quadrados, adquiriram proporção longílinea e ganharam profundidade em função da rígida padronização dimensional dos apartamentos da rede hoteleira. Administrado pela bandeira Ibis Rouge, do grupo Accor Hotéis, Hotel foi inaugurado em 2015 e está localizado no Bairro de Valongo em Santos, SP. A Figura 8 ilustra o Grafo visual topológico para este hotel.

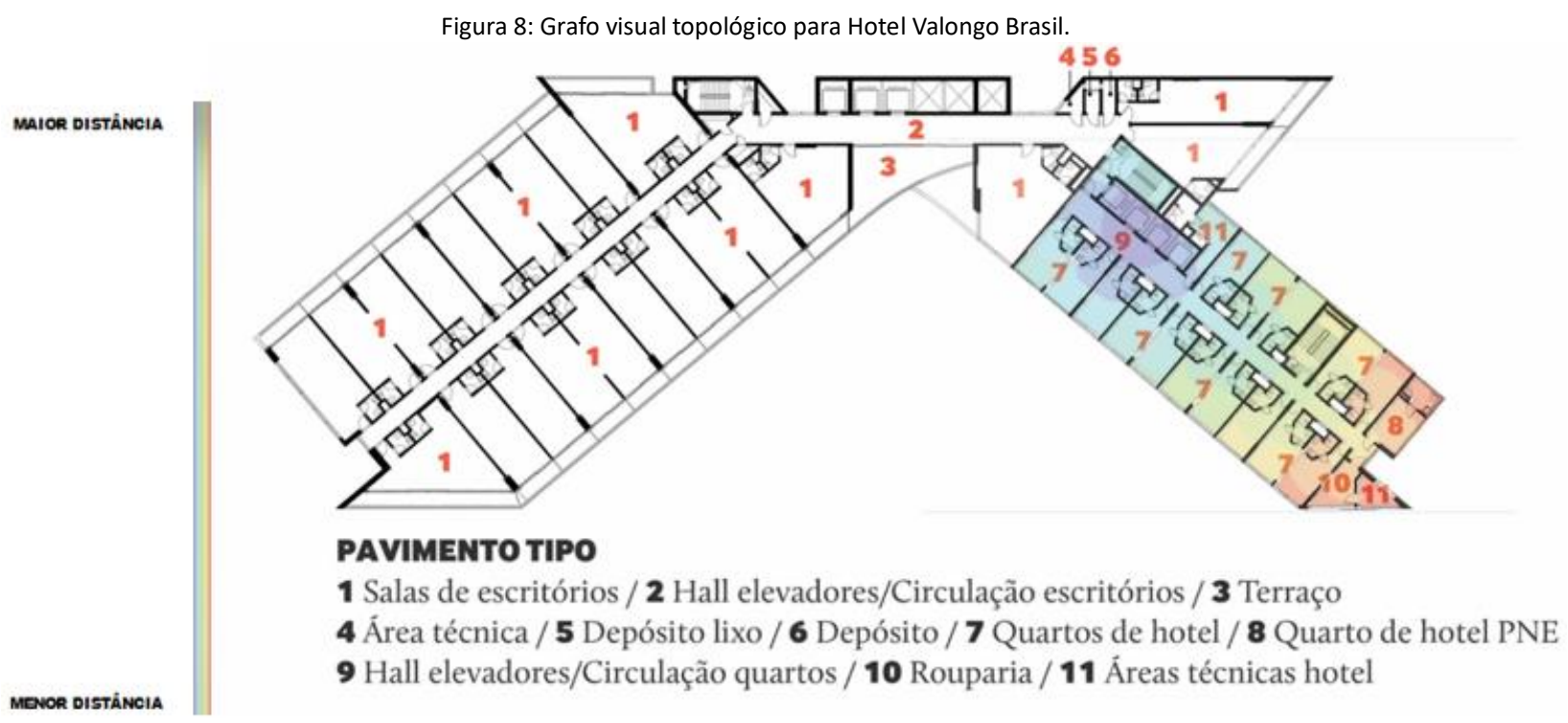

Fonte: Autor, 2020.

Da mesma forma que no exemplo anterior, é possível verificar que os dormitórios acessíveis também encontram-se nas regiões vermelhas e alaranjadas do grafo visual indicando que estão segregados em relação aos demais.

\section{Hotel Veleiros - Natal, RN}

Edifício da Construtora Hazbun, localizado na Av. Roberto Freire, projetado pela Arquiteta Olga Portela em 2005, conta com 22 pavimentos, sendo 18 deles de acomodações. o Hotel Veleiros tem projeto com área construída total de 7.552,51 $\mathrm{m}^{2}$. Há somente uma suíte acessível e apenas no primeiro pavimento. Na Figura 9 é possível verificar o grafo visual para este empreendimento. 

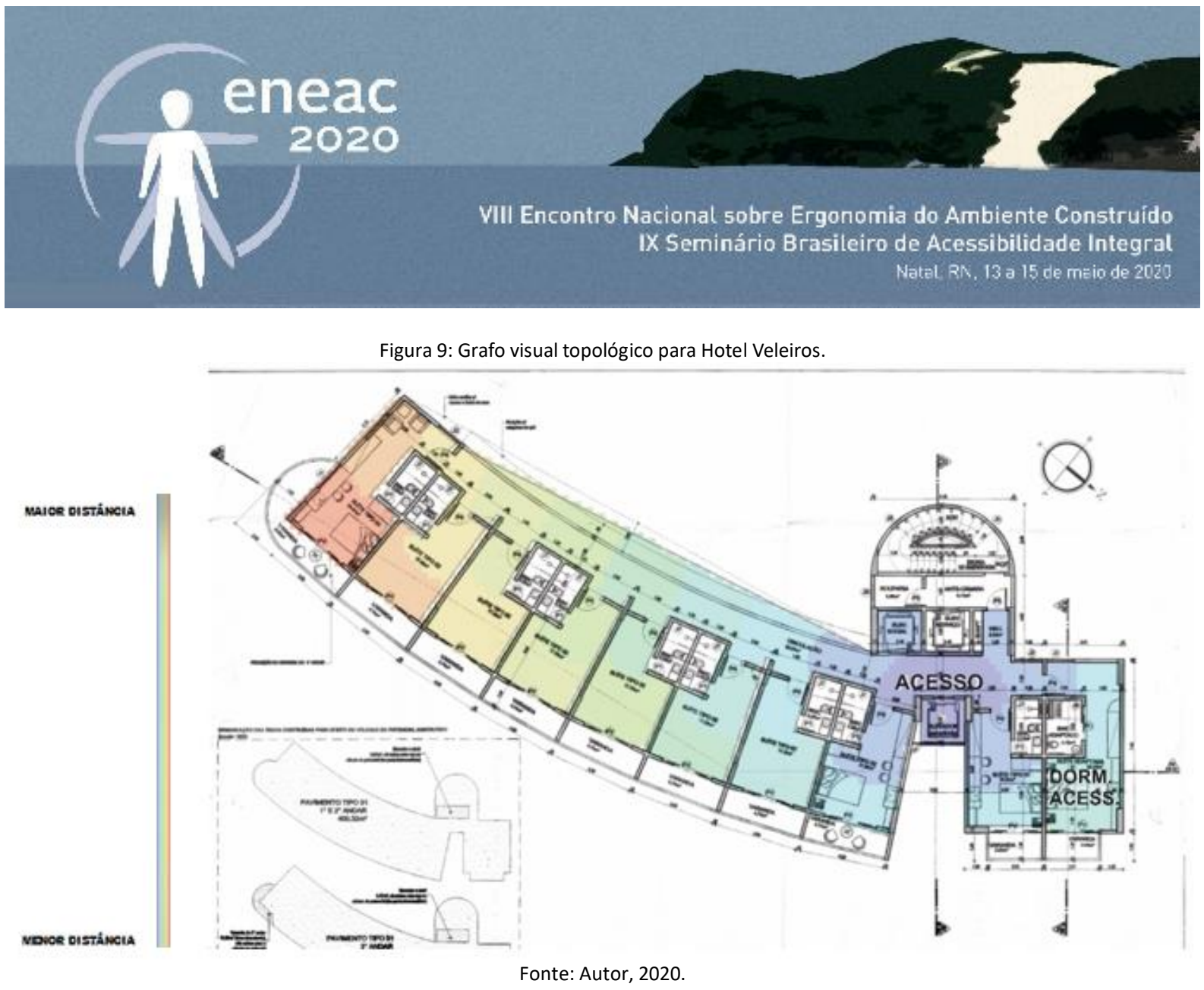

Contrariando o que ocorreu nos resultados dos hotéis Aliah e Valongo Brasil, no primeiro exemplar da cidade de Natal observou-se que os dormitórios acessíveis aparecem na região azulada do grafo visual, significando que estes cômodos são mais bem integrados que os demais dormitórios em relação à área de acesso do hall das suítes.

\section{Enseada Praia Hotel - Natal, RN}

Hotel localizado na Av. Eng.o Roberto Freire 4850 - Ponta Negra, foi inaugurado em 1998, conta com 50 acomodações. o Hotel Veleiros tem projeto com área construída total de $3.791,23 \mathrm{~m}^{2}$. Há somente uma suíte acessível e apenas no primeiro pavimento. $O$ projeto em análise é o de reforma da edificação protocolado há 24 meses antecedentes a este artigo. O Hotel permaneceu fechado para obras de adequações por 18 meses a partir de julho de 2018. Verifica-se na Figura 10 o resultado da análise topológica para este hotel. 

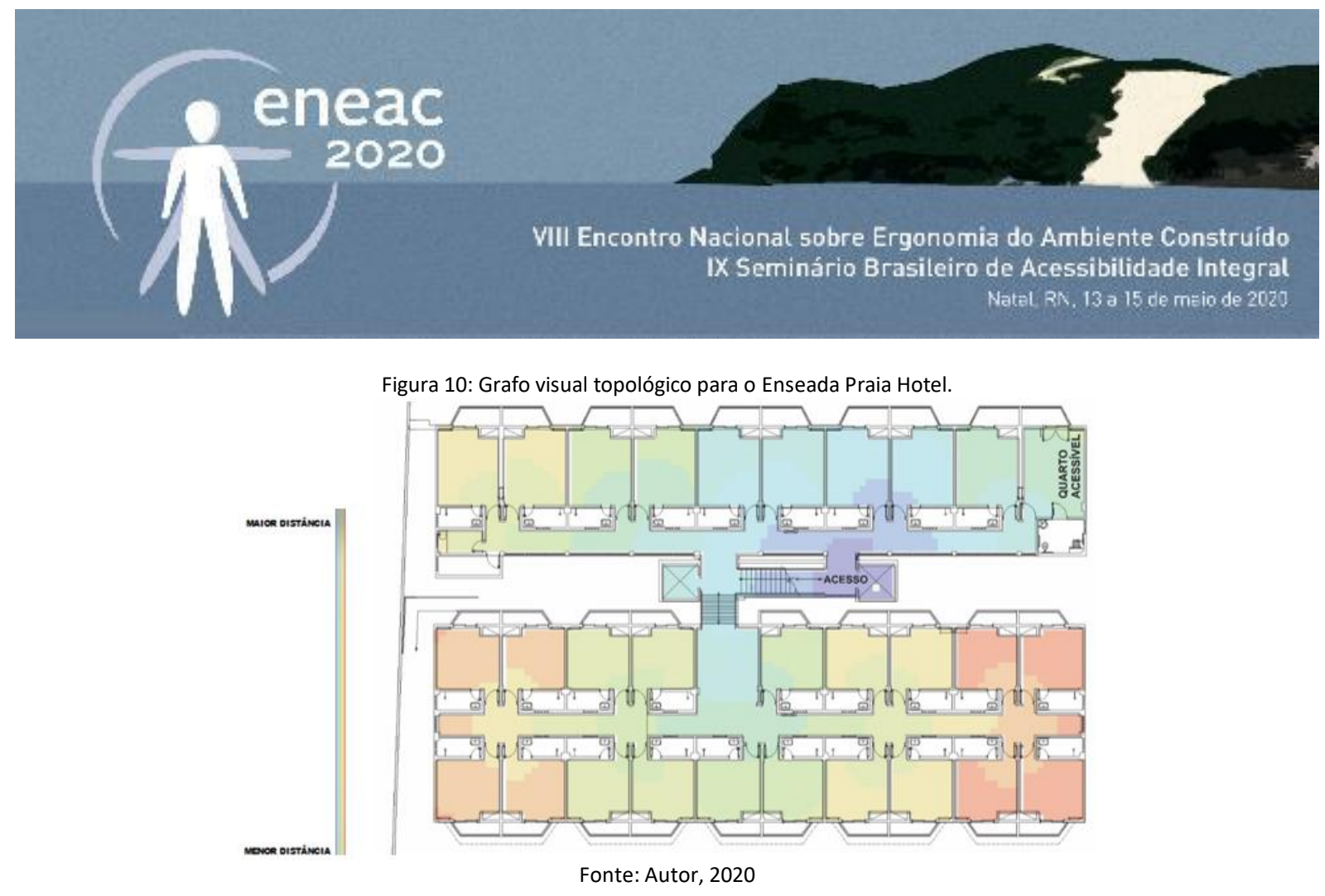

Da mesma forma que no primeiro hotel da cidade de Natal que foi analisado, o Enseada Praia Hotel apresenta seus quartos acessíveis na região azulada do grafo, implicando em quartos mais segregados que a maioria dos demais comuns situação nas regiões amarelo-avermelhadas.

\section{Natal Dunnas Hotel - Natal, RN}

Hotel com projeto de reforma da arquiteta Rita Macedo, está localizado na Av. Eng.․ Roberto Freire 5248 - Ponta Negra, conta com 102 acomodações. O Natal Dunnas Hotel tem projeto com área construída total de $3.791,23 \mathrm{~m}^{2}$ e em sua divulgação enfoca a disposição de acessibilidade em toda a extensão do mesmo. O projeto em análise é o de reforma da edificação protocolado na SEMURB em maio de 2017 e neste, prevê a inclusão de mais 04 dormitórios acessíveis, totalizando 05, um destes localizado no mesmo pavimento do setor administrativo e lazer, é a única acomodação neste piso e os 04 demais dispostos no primeiro pavimento, apesar do edifício possuir 04 níveis de acomodações. A Figura 11 mostra a análise topológica para este hotel.

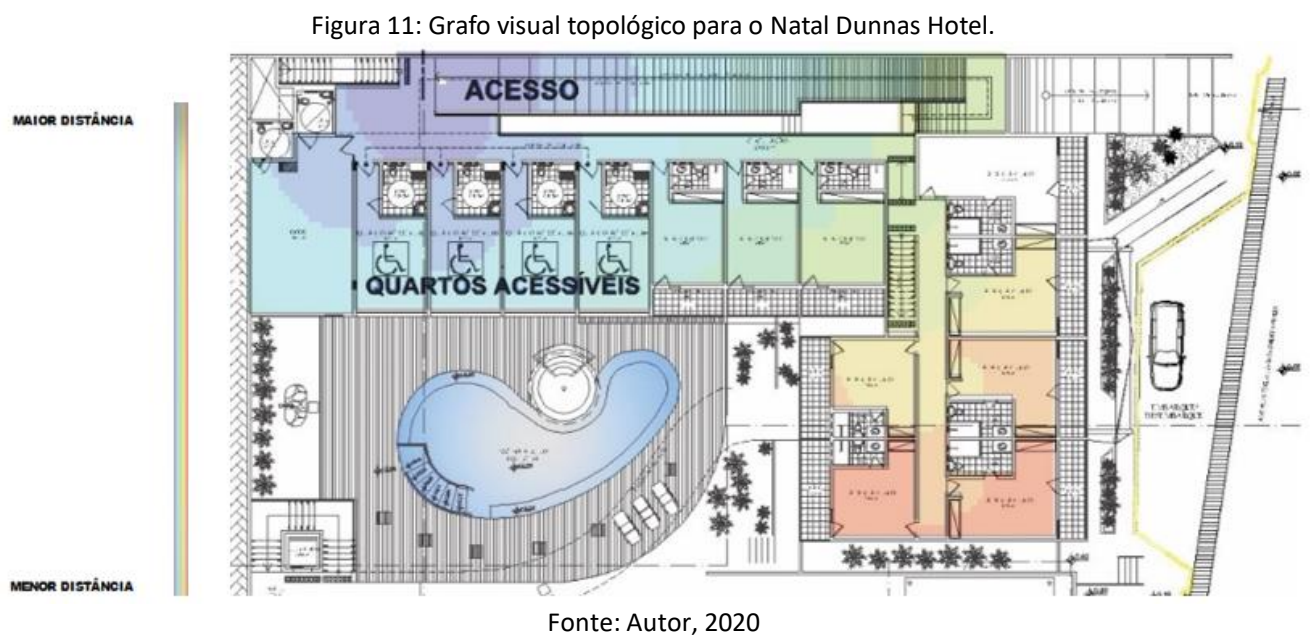




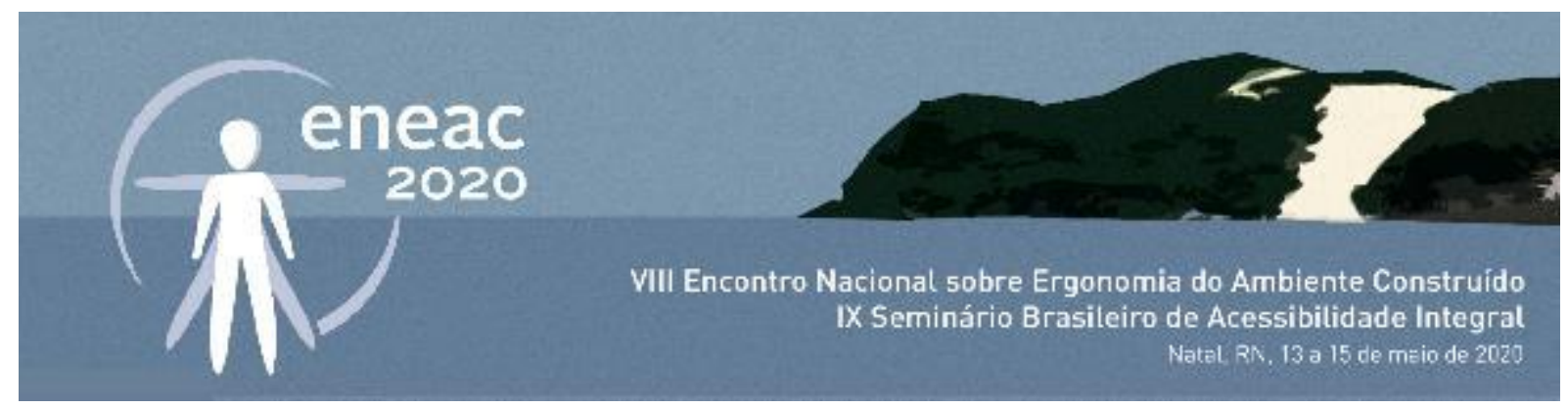

No Natal Dunnas Hotel, os quartos acessíveis, ao se situarem nas primeiras posições em relação à rampa de acesso ao hall das suítes tornam-se visualmente mais integradas que as demais suítes, sendo comprovada através da análise gráfica com a presença total da área azulada nestes ambientes.

\section{Vogal Luxury Hotel - Natal, RN}

Hotel com projeto do escritório de arquitetura Arctec, está localizado na Rua Cel. Inácio Vale, 33 Ponta Negra, conta com 105 acomodações distribuídas pelos 10 pavimentos da edificação. O Hotel Vogal tem projeto com área construída total de $11.805,27 \mathrm{~m}^{2}$ e possui 06 acomodações, destas, 03 no segundo pavimento e as demais no terceiro. Verifica-se na Figura 12 o resultado das análises para este hotel.

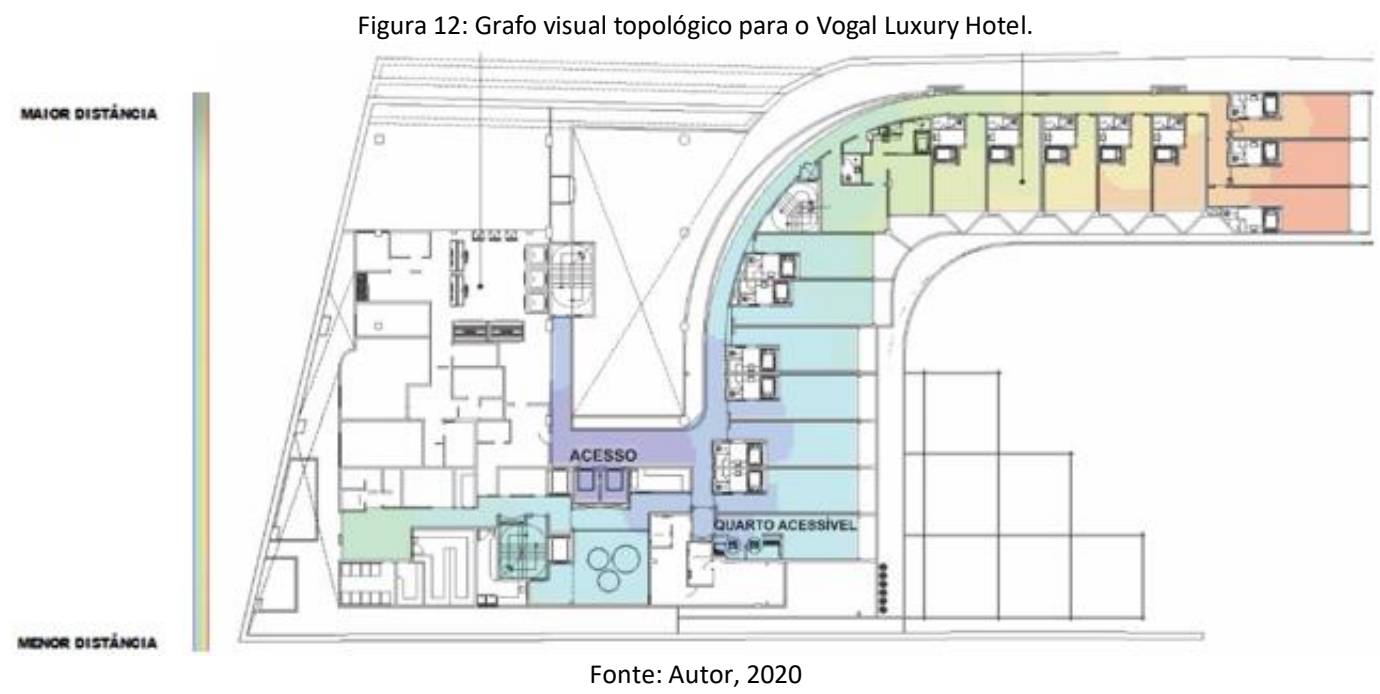

Por fim, no último dos hotéis avaliados em Natal, repetem-se os resultados observados nos demais conterrâneos em que os dormitórios acessíveis apresentam-se mais integrados que os demais tendo a vista a presença da região azulada neste ambiente.

\section{CONCLUSÕES}

Conclui-se que o método de avaliação de segregação de ambientes por meio das técnicas de sintaxe espacial com grafos justificados e visuais topológicos foi implementada de forma satisfatória, atingindo o principal objetivo deste trabalho.

Com relação aos resultados presumidos com a avaliação visual prévia aos procedimentos metodológicos nos hotéis de RJ e SP, conclui-se que estes apresentaram-se válidos visto que, sintaticamente, as suítes acessíveis neles presentes encontram-se segregadas das demais. 


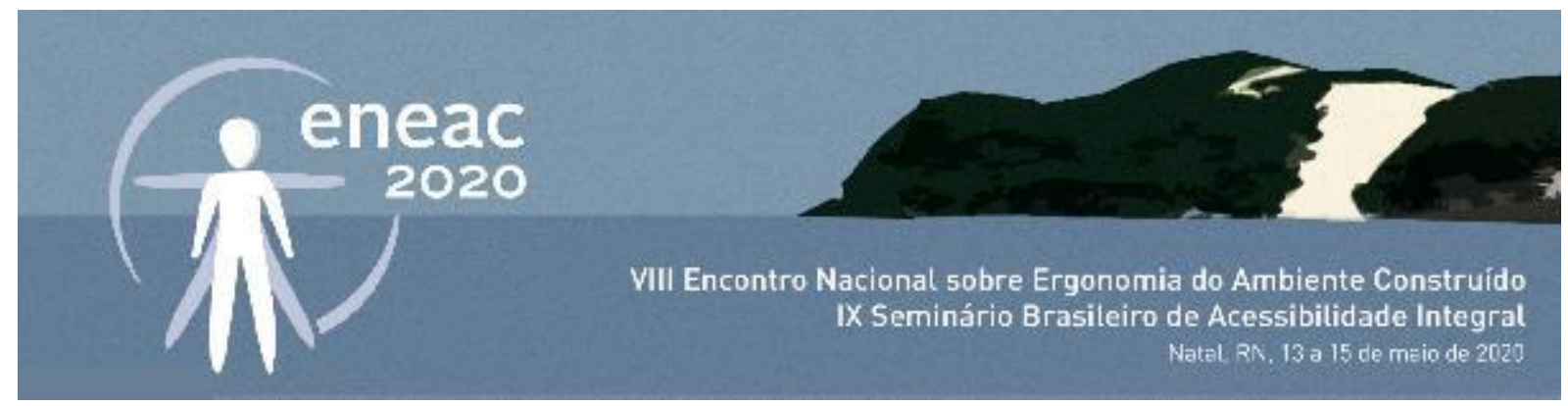

Os hotéis da cidade de Natal avaliados neste estudo apresentaram todos os dormitórios acessíveis bem integrados se comparados com as suítes comuns tendo em vista os resultados apresentados nos grafos visuais topológicos.

Apesar dos estudos demonstrarem que os hotéis em Natal, objetos desta produção acadêmica, apresentarem resultados satisfatórios em relação a integração dos quartos acessíveis, pôde-se constatar características construtivas que contribuem para a segregação de uma maneira geral. Como por exemplo a proximidade dos quartos às áreas técnicas e administrativas, redução da área dos quartos para compensação na área do banheiro e perda das varandas, disposição dos quartos em pavimentos limitados, desprovendo o hóspede da livre escolha e da apreciação do potencial cênico do entorno do hotel. É válido ressaltar a importância de levar adiante esta temática, visto que novos resultados poderão surgir com um número maior de objetos de análises.

\section{AGRADECIMENTOS}

Ao Programa de Pós-Graduação em Arquitetura, Projeto e Meio Ambiente da Universidade Federal do Rio Grande do Norte pela oportunidade de realizar esta pesquisa;

À Professora Edja Trigueiro pelo apoio e orientação;

À Secretaria Municipal de Meio Ambiente e Urbanismo - SEMURB, da cidade de Natal/RN pela disponibilização dos documentos necessários à realização deste trabalho.

\section{REFERÊNCIAS}

ASSOCIAÇÃO BRASILEIRA DE NORMAS TÉCNICAS. NBR-9050: Acessibilidade a edificações, mobiliário, espaços e equipamentos urbanos. Rio de Janeiro: Abnt, 2015.

BRASIL, Congresso Nacional. Lei Federal 13.146/2018. Institui a Lei Brasileira de Inclusão da Pessoa com Deficiência (Estatuto da Pessoa com Deficiência), 06 jul. 2015.

BRASIL, Congresso Nacional. Decreto Federal 9.296/2018. Regulamenta o art. 45 da Lei no 13.146, de 6 de julho de 2015, que institui a Lei Brasileira de Inclusão da Pessoa com Deficiência - Estatuto da Pessoa com Deficiência, 01 mar. 2018.

HILLIER, B.; IIDA, S. Network effects and psychological effects: a theory of urban movement. Proceedings of the 5th Space Syntax Symposium. Delft: TU Delft, Faculty of Architecture, Section of Urban Renewal and Management

RAMOS, H. CENTRO COMERCIAL AVENIDA: UM ESPAÇO ABERTO À CIDADE, 2018. Mestrado Profissional Em Arquitetura, Projeto E Meio Ambiente - UFRN.

RAMOS, H. CENTRO COMERCIAL AVENIDA: UM ESPAÇO ABERTO À CIDADE, 2018. Mestrado Profissional Em Arquitetura, Projeto E Meio Ambiente - UFRN.

SABOYA, R. Centralidade espacial: uma nova operacionalização do modelo baseada em um Sistema de Informações Geográficas, 2001. Dissertação de Mestrado, Porto Alegre: Propur - UFRGS.

SABOYA, Renato. Sintaxe Espacial - gráficos de visibilidade. 2011. Disponível em: <http://urbanidades.arq.br/2011/04/sintaxe-espacial-graficos-de-visibilidade-2/>. Acesso em: 05 fev. 2020.

<https://www.arcoweb.com.br/noticias/arquitetura/aflalogasperini-edificio-valongo-brasil-santos-sp>. Acesso em: 05 fev. 2020

<http://otp.spacesyntax.net/>. Acesso em: 05 fev. 2020 


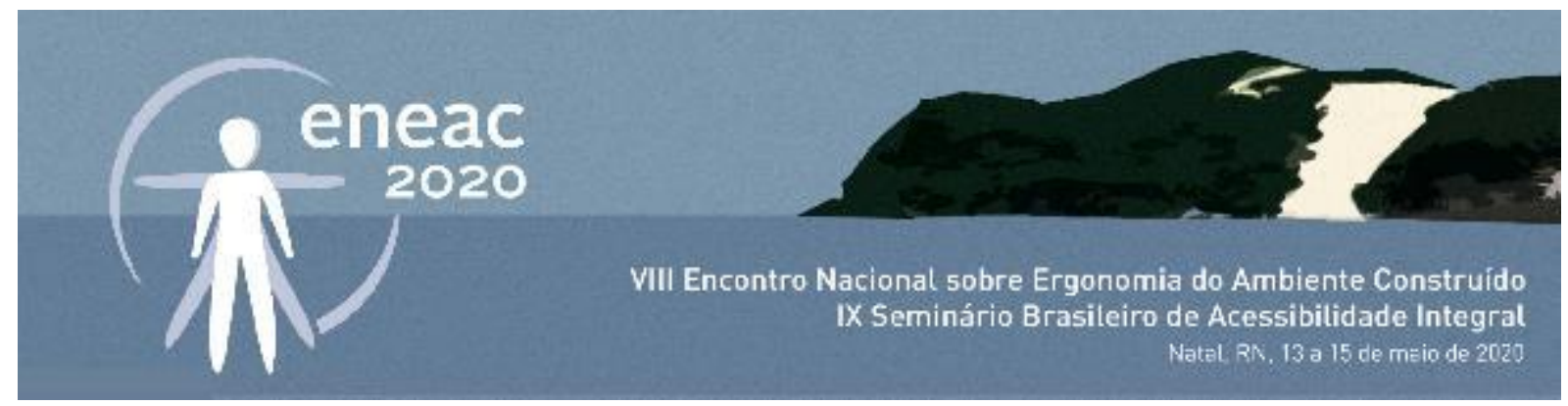

$<$ https://www.archdaily.com.br/br/805277/fatores-morfologicos-da-vitalidade-urbana-nil-parte-2-acessibilidade-renato-tde-saboya>. Acesso em: 05 fev. 2020

<https://www.archdaily.com.br/br/602555/hotel-linx-international-airport-galeao-slash-ospa-arquitetura-e-urbanismo>. Acesso em: 05 fev. 2020

<http://urbanidades.arq.br/2007/09/sintaxe-espacial/ >. Acesso em: 05 fev. 2020

$<$ https://aredeurbana.wordpress.com/2016/05/24/sintaxe-espacial-e-a-analise-angular-de-segmentos-parte-1-conceitos-emedidas/ >. Acesso em: 05 fev. 2020

$<$ https://aredeurbana.wordpress.com/2017/09/11/analise-de-isovistas-e-grafos-de-visibilidade-parte-1-conceitos-medidase-aplicacoes/>. Acesso em: 05 fev. 2020

$<$ https://aredeurbana.wordpress.com/2016/06/26/sintaxe-espacial-e-a-analise-angular-de-segmentos-parte-3-calculandomedidas-sintaticas/>. Acesso em: 05 fev. 2020

<http://www.vitruvius.com.br/revistas/read/arquitextos/15.171/5289>. Acesso em: 05 fev. 2020

\section{NOTAS}

i Acessibilidade: ao estudar as relações entre a variável escolha e a integração global, HILLIER et al. (1987) identificam que "a correlação entre essas duas variáveis indicará o grau de acessibilidade". Também afirma que tal correlação estabelece o potencial que o espaço analisado tem para movimentos "de passagem" ou "de/para" (equivalente à origem e/ou destino de viagens em transportes).

ii Conectividade de uma linha axial é a quantidade de linhas que a interceptam, ou seja, a quantidade de linhas que estão a uma profundidade (topológica) igual a 1 a partir dessa linha (SABOYA, 2007).

iii Um passo topológico se refere à noção de movimento em um sentido único, sem mudança de direção, desconsiderando a distância métrica entre pontos. Havendo uma mudança de direção ao movimentar-se, temos, por esta definição, dois passos topológicos. Medeiros diz que "em arquitetura, topologia é entendida com o estudo de relações espaciais que independem de forma e tamanho" (2013, p.38).

iv $O$ valor de integração traduz o potencial de movimento de uma via em relação às demais que compõe o espaço analisado. São calculados levando em consideração todos os caminhos possíveis, potencializando-se sua ligação com os demais "como se fossem medidos e hierarquizados os trajetos desenvolvidos por alguém que percorresse todas as vias da cidade, a partir de cada uma delas, sem jamais voltar sobre os seus passos" (HILLER; HANSON, 1984 apud GURGEL, 2012). 